\title{
Las "combis" interurbanas de línea. El caso de los servicios nacionales en la provincia de Buenos Aires
}

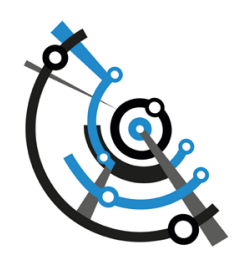

\author{
(4) Daniela Miglierina \\ Universidad de Buenos Aires, Argentina. \\ Orcid: org/oooo-0oo2-1996-1990 \\ Jorge Sánchez \\ Instituto de Transporte, Universidad Nacional de San Martín, Argentina. \\ https://orcid.org/oooo-0002-2178-4292
}

Recibido: 19 de noviembre de 2019. Aceptado: 15 de junio de 2020.

\begin{abstract}
Resumen
El trabajo indaga en el servicio de combis interurbanas como fenómeno relativamente reciente de prestación en las cortas y medias distancias en el marco de la competencia con otros servicios de transporte y en relación a las ciudades que vinculan. El origen del servicio es relativamente reciente respecto a otros modos, con especialización en distancias entre rangos de 100 a 150 y 300 a $350 \mathrm{~km}$, uniendo ciudades de porte chico/ medio con ciudades grandes. Los habitantes de las localidades de porte chico/medio tienden a recurrir a las ciudades de mayor tamaño en búsqueda de servicios que en ellas no tienen o tienen de manera escasa. Las altas frecuencias diarias, con amplitud horaria, en corredores de alto tránsito vehicular le otorgan una cierta "especialización geográfica" al servicio y una cercanía con los usuarios que las diferencian del servicio regular de ómnibus, su competidor más cercano. La visibilización del fenómeno en cuanto a la competencia que ejercen con los servicios de ómnibus regulares como también ante la falta de una entidad normativa explícita en el orden nacional para este tipo de práctica particular, deja al descubierto una cierta debilidad en el marco de la planificación territorial y del transporte.
\end{abstract}




\title{
The regular interurban van ["combi"] services. The case of national services in the province of Buenos Aires
}

\begin{abstract}
The work investigates the service of interurban combis as a relatively recent phenomenon of provision in the short and medium distances within the framework of competition with other transport services and in relation to the cities they link. The origin of the service is relatively recent compared to other modes, with specialization in distances in ranges between 100 to 150 and 300 to $350 \mathrm{~km}$, linking small / medium size cities with large cities. The inhabitants of small / medium-sized towns tend to resort to larger cities in search of services that they do not have or have scarcely. The high daily frequencies, with time amplitude, in high traffic corridors give a certain "geographical specialization" to the service and a closeness with the users that differentiate them from the regular bus service, their closest competitor. Making the phenomenon visible regarding the competition they exercise with regular bus services as well as the lack of an explicit regulatory entity in the national order for this particular type of practice, reveals a certain weakness in the territorial planning framework and of the transport.
\end{abstract}

Intercity transport. Van ["combis"] services. Bus services. Short interurban distance. Geographical specialization.

Transporte interestadual. Serviços de fretado ou van. Serviços de ônibus. Distâncias curtas entre cidades. Especialização geográfica.

\section{Introducción}

El desplazamiento de personas en la larga distancia en Argentina, como fenómeno de masas, ha mostrado permanentes modificaciones a lo largo de su historia. Solo por mencionar algunas de ellas, desde los aspectos motivacionales, duración de las travesías - a partir de nuevas tecnologías en los modos de transporte o de más y mejores caminos pavimentados y de mayor capacidad -, hasta los tiempos destinados a la ausencia fuera del lugar habitual de residencia de los viajeros.

Los últimos 25 años han visto tres cambios notables en los desplazamientos de cabotaje de personas respecto a las opciones modales. Por un lado, y de manera central, la consolidación del automóvil particular para el grueso de los viajes en distancias cortas y medias; en segundo lugar, la creciente presencia del modo aéreo para las mayores distancias; $y$, por último, la aparición de un sistema nuevo en minibuses/combis/vans ${ }^{1}$ que, surgiendo como oferta no regular en distancias cortas interurbanas, culminaron haciendo línea, término que refiere a un servicio con frecuencias predeterminadas en días y horarios y de libre acceso al público mediante el pago del servicio.

Estas tres modalidades se desarrollaron en un escenario de crecimiento global de los viajes y de la tasa de viaje por habitante desplazando, también, a los ómnibus regulares característicos de las décadas de los 60', 70', 80’ y parte de los 90'. El objeto de análisis de este trabajo son los servicios prestados en las "combis interurbanas de línea".

1 Se trata de un vehículo automotor tipo furgón usado para el transporte de personas. En la Argentina el nombre usual con que se denomina a estos vehículos automotores es "combi”. Su nombre deriva de la icónica camioneta Volkswagen Kombi y su definición se encuentra, incluso, en el diccionario de la Real Academia Española. El término "van" es una apócope de la palabra inglesa "caravan", casa rodante o camioneta, y su uso es menos frecuente en la Argentina. 
El servicio de combis interurbanas de línea se desarrolló uniendo ciudades de pequeño/ mediano porte con ciudades grandes (por ejemplo, Ciudad Autónoma de Buenos Aires, La Plata, Rosario, etc.), con una distancia promedio comprendida entre los rangos 100 a $150 \mathrm{~km}$ y 300 a $350 \mathrm{~km}$. Salvo excepciones, las ciudades chicas/medianas tienden a ser generadoras de viajes mientras que las de gran porte tienden a ser atractoras. Las excepciones se dan cuando la localidad pequeña tiene alguna particularidad distintiva como por ejemplo, ser un lugar turístico; es el caso de la relación existente entre Buenos Aires y la ciudad balnearia de Mar del Plata donde la atractora es esta última.

Dado que el servicio de combis es relativamente nuevo respecto de las restantes ofertas modales en medias distancias, cabe preguntarse por qué el servicio se ha consolidado y una porción de la población viajera las utiliza intensivamente. Como también, cuáles son las características más comunes de este servicio, qué condiciones se cumplen en los corredores donde se desenvuelven, cuál es la participación relativa que allí tienen, cómo compiten con los otros modos, cuáles son los marcos normativos que permiten la actividad, en qué medida representan un problema para los servicios de ómnibus de larga distancia, entre otros.

Paralelamente, en el orden de las necesidades de desplazamiento de la población que opta por este servicio surgen preguntas tales como qué actividades motivan los desplazamientos entre las ciudades chicas/medianas y las grandes, qué demandan los habitantes de ciudades a las de mayor porte, qué patrones de viaje se configuran en las distancias cortas entre ciudades chicas y grandes.

El trabajo es un estudio descriptivo de un fenómeno invisibilizado tanto desde los estudios académicos como desde el ámbito de la política pública. Concretamente, el documento se concentra en tratar de responder los interrogantes planteados partiendo de un marco conceptual que delinea las condiciones de borde de los análisis; luego se describe al sistema de combis interurbanas desde su origen, su desenvolvimiento, la competencia con otros modos, las preferencias de los usuarios y su situación actual operando al margen de la normativa vigente, con especial énfasis en tráficos nacionales, para finalizar con las conclusiones se expresa una breve reflexión acerca de la visibilización del fenómeno. Los tráficos nacionales son aquellos que, independientemente de los orígenes y destinos de los viajes, en su recorrido atraviesan al menos un límite provincial. Por su parte, los tráficos provinciales son aquellos que discurren íntegramente dentro de un territorio provincial siendo la provincia en donde operan la autoridad de regulación y control.

\section{Consideraciones metodológicas}

Dadas las limitaciones para la obtención de información del fenómeno combis, fueron elaboradas y articuladas distintas estrategias que colaboraron con la indagación del objeto estudio. El escenario de información estadística y de registros oficiales de combis es incompleto ya que no se tiene totalmente identificado el universo de los vehículos y empresas que operan en la oferta de estos servicios. Las estadísticas suelen agrupar los diversos usos que se hacen de las combis (servicios de oferta libre, servicios de transporte para el turismo urbanos). Como consecuencia, no se tiene un conocimiento global y exclusivo desde las fuentes oficiales de esta modalidad prestada por las combis.

Por lo tanto, el avance se realizó a partir de la complementación de información diversa, tal como: registros de la Comisión Nacional de Regulación del Transporte (CNRT), estudios de corredores específicos de la Cámara Empresaria de Larga Distancia (CELADI), análisis normativo y entrevistas a actores clave del transporte interurbano 
(cámaras de empresarios, transportistas, funcionarios de planificación del transporte, especialistas en normativa interurbana), a los que también se le sumaron entrevistas y sondeos a usuarios frecuentes del servicio de combis de línea. El criterio de la selección de datos se realizó en función de una selección de organismos y actores estratégicos que se ven afectados tanto como oferentes, competidores o usuarios de las combis. A continuación se detalla cada fuente y análisis realizado:

" Normas. Con el propósito de reconocer el marco dentro del que opera el servicio de combis, se relevaron normas asociadas a la oferta se servicios nacionales de combis. Las normas relevadas son: Decreto 958/92, Resolución Secretaría de Transporte (ST) 374/92, Resolución ST 11/93, Decreto 808/95, Resolución 127/2001, Resolución ST 13/2002, Decreto 2404/2002 y Decreto 427/2017.

»Estudio de corredores de la Cámara Empresaria de Larga Distancia (CELADI), junio de 2016. Se analizó un relevamiento de casos de corredores de combis de línea que compiten con servicios de ómnibus regulares en la larga distancia. Los relevamientos contemplan en distintos corredores: pares origen - destino de los servicios, frecuencias en días de semana y fines de semana, butacas disponibles y empresas. Los corredores son: Ruta Nacional 3, Ruta Nacional 205 y Ruta Nacional 9 entre Ciudad Autónoma de Buenos Aires (CABA) y localidades cercanas.

»Estadísticas CNRT. Revisión de estadísticas disponibles asociadas a la participación del parque de los vehículos registrados como servicio de transporte para el turismo del año 2016, provista por la Dirección Nacional de Planificación de Transporte Interurbano e Internacional de Pasajeros en el año 2017.

"Entrevistas. Las entrevistas estuvieron dirigidas a distintos actores que de alguna manera son afectados por el servicio de combis. Por un lado, se entrevistaron referentes de organismos públicos de carrera de $\mathrm{CNRT}^{2}$, a técnicos de la Dirección Nacional de Planificación de Transporte Interurbano e Internacional de Pasajeros ${ }^{3}$, de la Cámara de empresarios de Larga distancia (CELADI) ${ }^{4}$, de la Asociación Argentina de Empresarios de Transporte (AAETA) $)^{5}$. Como también fueron entrevistados empresario de ómnibus ${ }^{6}$ y Alberto Muller de CESPA, Facultad de Ciencias. Económicas UBA. Los temas desarrollados fueron: opiniones acerca de la operación actual de las combis, los condicionamientos y vacíos del marco normativo, el funcionamiento del sistema de registros y la competencia con los servicios de buses. Por otro lado, se realizaron entrevistas a transportistas que efectivamente prestan servicios de combis de línea ${ }^{7}$. Por último, se realizaron entrevistas a usuarios frecuentes, complementariamente a sondeos a grupos de viajeros en puntos de ascenso del servicio (shopping Alto Palermo y esquina Ecuador y Sarmiento), en donde se relevaron variables típicas como: frecuencias, motivos de viaje, motivos de elección del servicio.

" Observación participante y no participante. Se realizaron observaciones en puntos de ascenso y descenso de pasajeros en sitios específicos de la CABA y sedes de las empresas (shopping Alto Palermo y esquina Ecuador y Sarmiento). Los lugares fueron elegidos por ser puntos de llegada y partida de servicios de combis de línea. El propósito fue identificar el uso frecuente que hacen los pasajeros, prácticas de

2 Guillermo Cozzi, Roberto Domecq y Salomé Chirdo.

3 Eduardo Parodi.

4 Mario Rossi.

5 Marcelo Gonzálvez y Flavio Nicolino.

6 Hugo Luis Teruel de la empresa Plusmar.

7 Empresa de combi de Trelew y transportista empresa de Chivilcoy, prestadores de servicios de combis de línea. 
prestación del servicio, revisión de controles efectuados a los prestadores, condiciones de los paradores, entre otras cosas.

"Llamados a empresas. Fueron seleccionadas las empresas que participan en los corredores estudiados por la Cámara Empresaria de Larga Distancia (CELADI) en el año 2016. ${ }^{8}$ Permitieron cotejar condiciones de prestación de servicios tales como: horarios, condiciones para la repartición de pasajeros, lugares donde tomar el el servicio, como también permitió estimar la ocupación vehicular de los servicios en distintos momentos de la semana (día hábil o fin de semana).

"Información en páginas web. El relevamiento web de empresas prestatarias de estos servicios permitió complementar la información recabada desde los llamados telefónicos, tales como la información formal de días, horarios, tipos de servicios que prestan, puntos de ascenso y descenso de pasajeros. La selección de casos también se realizó desde los corredores estudiados por la Cámara Empresaria de Larga Distancia (CELADI, 2016). Las páginas web se detallan en el apartado de bibliografía $\mathrm{y}$ otras fuentes de datos.

"Relevamiento bibliográfico. Revisión de conceptos clave que colaboraron con el entendimiento del fenómeno, desde donde también se puede interpretar una lógica de funcionamiento a través de las relaciones entre ciudades y redes de circulación territorial así también las nuevas formas de comprender la movilidad. La bibliografía revisada se detalla en el apartado de bibliografía y otras fuentes de datos.

\section{Marco de interpretación para el análisis del transporte interurbano en las cortas distancias}

El fenómeno de las combis se propone revisarlo con relación a dos perspectivas de análisis. Por un lado, a través del marco de entendimiento de las jerarquías urbanas y redes de circulación con el fin de comprender la lógica en la que se inscriben los desplazamientos entre ciudades de distinto porte y con relación a distintas escalas (local, regional, global). Esto se corresponde con que el fenómeno de las combis se inscribe en un contexto de interacción particular entre ciudades de distinta jerarquía urbana, particularmente entre grandes aglomerados urbanos (generalmente metropolitanos) y ciudades chicas o intermedias en distancias cortas y medianas (entre 100 a 150 y 300 a $350 \mathrm{~km}$ aproximadamente).

Paralelamente, se lo revisará desde el paradigma de la movilidad (Sheller y Urry, 2018) dado el interés de comprender también las formas de habitar el territorio desde la perspectiva de los nuevos usos de transporte, sin limitarse a las tradicionales maneras de revisarlo a través del análisis origen y destino de los desplazamientos (Hernández y Witter, 2011). Esta perspectiva colabora con las nuevas adaptaciones de la población que requiere desplazarse en las cortas distancias.

En cuanto a al análisis a través de las jerarquías urbanas, el trabajo se apoya en el estudio Argentina Urbana (Ministerio de Planificación Federal, Inversión Pública y Servicios, 2011). Éste considera que la preponderancia relativa de la ciudad en el territorio y los diferentes grados de complejidad de las funciones urbanas, dependen de las características propias del nodo urbano (equipamiento e infraestructura) y las relaciones con el resto del sistema. Ambos aspectos están de alguna manera conectados, bajo el supuesto de que a mayor equipamiento e infraestructura se dan mayores demandas y flujos de bienes y personas. 
El estudio mencionado también expresa que históricamente los análisis de jerarquización del sistema urbano se han basado en la identificación de los núcleos urbanos como lugares centrales para el desarrollo del comercio y la prestación de servicios. Las funciones de los centros urbanos se consideraban distribuidas a lo largo de una jerarquía que se iban complejizando desde los núcleos más simples, en cantidad y variedad de bienes y servicios ofrecidos. El resultado es un territorio piramidal, cuya parte superior ofrece las funciones más complejas que se reducen a medida que se desciende en la jerarquía. Ricot (2012) reconoce en la región pampeana una diversidad de centros de distintas escalas y rango de servicios, los cuales los asocia a la idea de Christaller (1966) de jerarquía de centros complementarios bajo un modelo de anillos hexagonales que definen áreas de influencia agropecuarias alrededor de aglomeraciones urbanas, concebidas como centros de servicios de distintas escalas.

Sobre la base del modelo de organización de los sistemas urbanos se observan nuevas dinámicas necesarias para comprender la complejidad de las relaciones entre los núcleos, los procesos de competencia y complementariedad, las articulaciones selectivas con la economía global, el papel en el comando de los circuitos del capital, las vinculaciones a distancia, los procesos de metropolización, la ampliación de relaciones cotidianas y la formación de redes regionales y transfronterizas (Ministerio de Planificación Federal, Inversión Pública y Servicios, 2011).

Las interrelaciones entre ciudades pueden estar dadas en distintas escalas geográficas: global, regional y local. Las grandes ciudades pueden también estar vinculadas con otras interrelaciones globales con impacto en la organización local (Rodrigue, 2017). A través de la articulación de escalas y selectividad territorial, la economía global está inmediatamente presente en la economía local. Los actores se despliegan en distintas instancias territoriales vinculando los lugares con lo local. Las redes técnicas tienen diversas escalas articuladas, por ejemplo, redes de capilaridad que alimentan redes troncales de circulación (Blanco, 2015).

Para Santos (2000) y Blanco (2015), las redes permiten articular escalas y seleccionar territorios, ponen en juego prácticas de los actores que atraviesan las escalas y promueve la selectividad territorial, es decir, solidariza elementos y excluye a otros a partir de la selección de nodos y canales. La fluidez es selectiva y profundiza procesos de diferenciación socio-territorial, dado que el aumento de las disparidades en función de la difusión tecnológica acentúa diferencias sociales. Blanco (2015:15) enfatiza que la "circulación" es una condición para el desarrollo del modelo de producción vigente, que alimenta la demanda de mayor velocidad. En este marco, las redes son garantes de fluidez, aseguran eficiencia y velocidad de los flujos. La manifestación de la fluidez es la velocidad y la velocidad es un imperativo del mundo contemporáneo que incide sobre los tiempos de rotación del capital, reduciendo ciclos de valoración.

Los corredores por donde circulan tanto las mercancías como las personas y que unen estas ciudades demandan incrementos de la velocidad (requisito de la economía global). Tal como expresa Rodrigue (2017), el impacto del transporte en la estructura espacial se vuelve multi-escalar, sobre todo en la era de la globalización en donde se dan relaciones complejas entre lo local y lo global promovidos por los procesos económicos contemporáneos. Dichos procesos demandan un significativo incremento en la movilidad y un aumento en los niveles de la accesibilidad.

La relación entre las ciudades cobra sentido a partir del sistema de transporte, el cual puede variar en función de tres consideraciones geográficas básicas: las características de localización (actividades, recursos, producciones, servicios, fuentes de trabajo) que determinan la naturaleza, los orígenes, los destinos y las distancias de los desplazamientos a realizarse; la complementariedad entre ciudades que ofrecen atributos (oferta de 
trabajo, recursos) que otras carecen, generándose movimientos entre ambas localidades; $y$, en tercer lugar, la escala asociada a distintos niveles en los que se pueden generar esos movimientos (locales, regionales, globales) (Rodrigue, 2017).

Entre el transporte y el espacio se genera una reciprocidad articulada en función de la reciprocidad de las localizaciones (sistema de transporte e impacto en las localizaciones, organización espacial del sistema, transporte, estructura espacial) y reciprocidad de la demanda (actividades que dependen del transporte en distintos niveles y escalas). Cuanto más interdependiente es una economía más importante se vuelve el transporte como soporte y factor que define la interdependencia.

El caso específico de la Región Metropolitana de Buenos Aires-La Plata oficia de nodo internacional y cumple con la función de intermediación con flujos a escala internacional y nacional, propio de una economía compleja, mientras que en la mayoría de los nodos microrregionales predominan las funciones de producción relacionadas con actividades agropecuarias, extractivas e industriales. Particularmente la región pampeana, la cual mantiene una función económica especializada en la producción agropecuaria, caracterizada por su inserción directa en la economía global y por una organización de la producción basada en la aplicación de un sofisticado paquete tecnológico y una mecanización del trabajo rural (Ministerio de Planificación Federal, Inversión Pública y Servicios, 2011).

De acuerdo con el trabajo Argentina Urbana (Ministerio de Planificación Federal, Inversión Pública y Servicios, 2011) los desplazamientos entre ciudades se generan en mayor medida mediante motorización particular la cual viene a reemplazar los desplazamientos ferroviarios que fueron desmotivados por el desmantelamiento del sistema ferroviario de pasajeros en la década del noventa. Paralelamente, en el área pampeana se observa una alta densidad de desplazamientos de transporte automotor de pasajeros interurbano, asociado con el mallado urbano regular. La gran concentración se refleja en los volúmenes de tránsito de los corredores radiales que confluyen hacia la Región Metropolitana de Buenos Aires-La Plata (como también en Rosario, Córdoba y Santa $\mathrm{Fe}$ ), tramos en los que se presencian todos los niveles de la jerarquía urbana asociados a las cortas distancias entre nodos. Tal como se observa en el mapa a continuación, los patrones de los flujos destacan el rol de los nodos mayores de la jerarquía que ofician de articuladores del territorio en diversas escalas. 

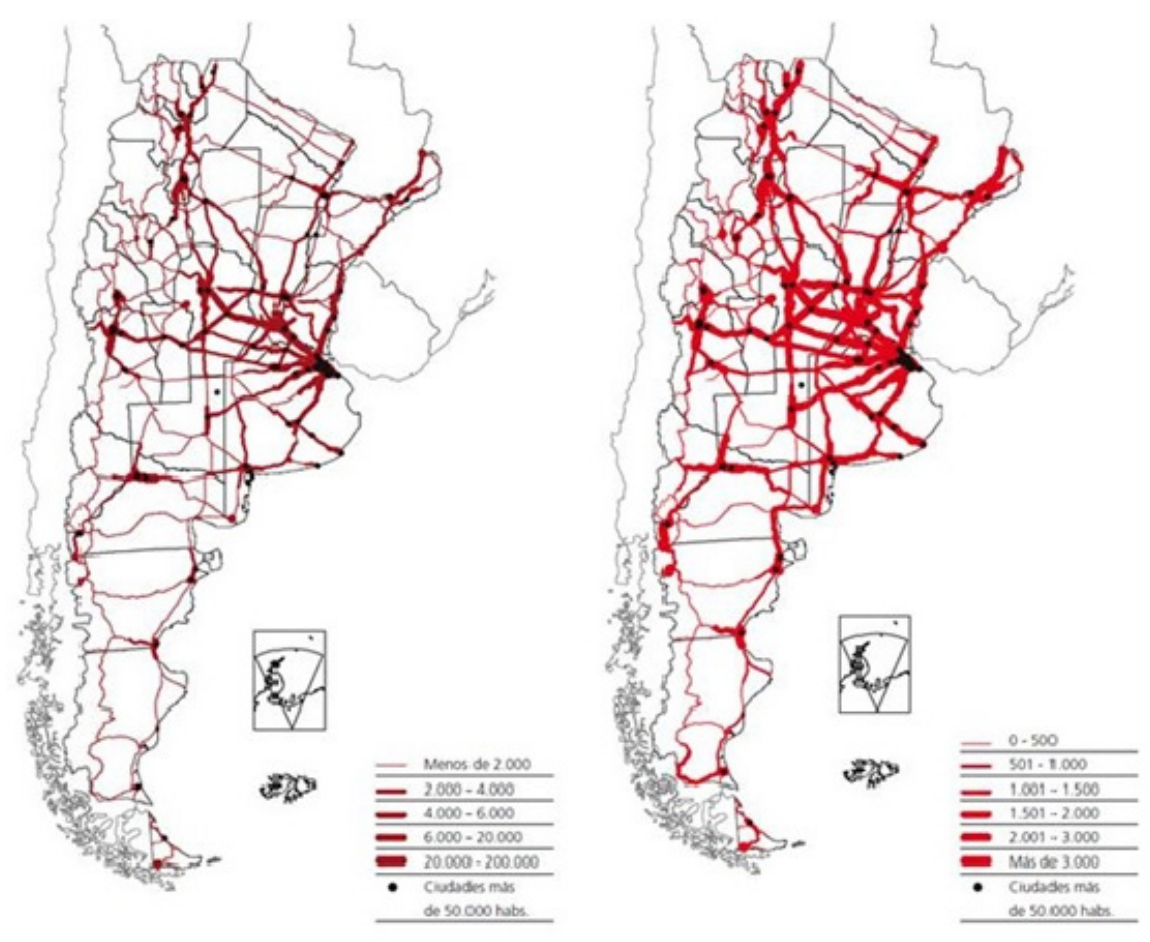

Figura 1. Tránsito medio diario anual de ómnibus en rutas nacionales. Figura 2. Tránsito medio diario anual de todos los vehículos pasantes por rutas nacionales. Fuente: Subsecretaría de Planificación de Transporte interurbano de Pasajeros (SPTIP), en base a datos de la Dirección Nacional de Vialidad (2009).

Paralelamente a las conceptos presentados, el presente trabajo también toma en consideración el paradigma de la movilidad con el objetivo de poner en discusión o comprender formas de habitar el territorio trascendiendo los estudios tradicionales del transporte que se ciñen a un análisis origen y destino de los desplazamientos (Sheller y Urry, 2018; Hernández y Witter, 2011).

Tal como cita Zunino (2018) a Sheller y Urry (2006) el nuevo paradigma de la movilidad se asocia a tomar la movilidad como un enfoque de observación de cualquier fenómeno social. En este sentido, se propone repensar a las prácticas cotidianas de viaje como experiencias en donde la movilidad cobra importancia en la producción del espacio, como un momento de experiencias y no meramente como un tiempo muerto de desplazamiento entre un punto y otro del espacio. La observación de la experiencia puede aproximarse a través de preguntarnos cómo aprendimos a movernos así, de qué modo hemos internalizado las prácticas para movernos o si siempre fueron iguales (Zunino, 2018).

La posibilidad de incorporar otras perspectivas de estudio de la movilidad habilita a repensar, entre otras cosas, los modos en los que se desplaza la población sin limitarse a un modo típico. Esto es posible desde una incorporación de miradas desde otras perspectivas asociadas a las experiencias y percepciones (Zunino, 2018).

Asimismo, las prácticas sociales pueden tener consecuencias no planeadas derivadas de la forma en que las personas usan, innovan y combinan diferentes sistemas, sin atarse a las nuevas tecnologías como también las viejas. El nuevo paradigma reconoce la necesidad de analizar redes, relaciones, flujos y circulación, sin focalizar en lugares fijos. Lo cual replantea la tradición en la teoría social de revisar al espacio como un contenedor para los procesos sociales. También reconoce, que las posibilidades de desplazamientos de las personas varían entre grupos sociales según las relaciones de 
poder en el tiempo. Por esta razón, la movilidad está vinculada a diferentes contextos históricos organizados a través de constelaciones particulares de movilidades desiguales (Sheller y Urry, 2018; Barañano Cid, 2016).

Esto nos permite interpretar, a partir de un nuevo campo de estudio, las formas en que las prácticas sociales de la movilidad cambiaron en distintos momentos de la historia como a futuro, yendo más allá de una mera interpretación a través de la elección del transporte. Abre paso a la comprensión de los sistemas de infraestructuras, entornos construidos, usos del suelo, externalidades ambientales (Sheller y Urry, 2018), como también el reconocimiento de movilidades no identificadas por los registros oficiales (Gutiérrez, 2012).

\section{El lábil marco normativo para desarrollar servicios de combis de línea}

Los servicios de combis de línea de larga distancia no tienen entidad normativa ni en el orden nacional ni en las jurisdicciones provinciales. En el orden nacional, la totalidad de los transportistas ingresan al sector a través de los denominados "Servicios de Transporte para el Turismo" establecidos en el Decreto 958, de junio de 1992, donde se encuentran normadas las diferentes modalidades operativas de los servicios de pasajeros de larga distancia de jurisdicción nacional. Debe quedar claro que ingresar al sector significa, básicamente, registrar los vehículos y contar los conductores con su licencia nacional habilitante ya que la operación que realizan estos servicios de combis está fuera de norma.

En el artículo 15 del Decreto 958/1992 se establece que el servicio de transporte para el turismo es aquel que se realiza con el objeto de atender a una programación turística. Por lo tanto, se trata de servicios que deben ser contratados por contingentes para realizar el transporte en un circuito cerrado que culmina en el punto mismo de partida.

El Decreto 958/1992 considera la importancia de adaptar el régimen del transporte automotor de pasajeros a los principios de apertura y competencia que había implementado el Gobierno Nacional en otros sectores de la actividad productiva y de otras ramas del transporte, bajo la justificación de que la demanda de servicios de transporte de pasajeros se había incrementado y se iba a seguir incrementando en el futuro como consecuencia de la reconversión de los servicios ferroviarios y de las ventajas relativas que aquéllos presentaban en materia de flexibilidad y diversidad.

¿Cuáles son los típicos servicios para el turismo? A raíz de las diversas entrevistas realizadas se verificó que son los que cubren los viajes estudiantiles o los tours de jubilados. En estos casos se utilizan vehículos de alta capacidad relativa de transporte (60 asientos) característicos de los servicios regulares por lo que varias empresas de estos últimos servicios también tienen registrados algunas de sus unidades en el registro vehicular correspondiente.

Asimismo, las entrevistas también dieron cuenta que hay muchos servicios turísticos que se ofrecieron desde un principio en unidades más pequeñas con origen de sus viajes en ciudades de porte medio para contingentes también pequeños en servicios de ida y vuelta en el día para realizar compras en ciudades más grandes, en especial Buenos Aires. De hecho, este es el origen de los transportistas de combis de línea de la primera generación, surgida en los años 90'.

Hacia los primeros años de vigencia del Decreto 958/1992, cuando las combis comenzaron a hacer línea, dos eran las ventajas económicas que tuvieron sobre su competidor 
más cercano como lo era el ómnibus regular. Por un lado, el personal de conducción, que explica una porción significativa del costo total de producción de los servicios, se encontraba en el convenio laboral de comercio cuando no era el mismo transportista el que operaba de conductor, lo que lo situaba en un trabajador cuenta propia sin ningún encuadre laboral. Frente al convenio laboral Unión Tranviarios Automotor (UTA) correspondiente a servicios regulares de larga distancia (interurbanos) los costos de personal de las combis eran sustancialmente inferiores. Este punto trató de salvarse al establecer en el convenio laboral del sindicato UTA, en el año 2010 (Convenio Colectivo de Trabajo 610/10), un convenio referido a los Servicios de Transporte para el Turismo firmado entre la Unión Tranviaria Automotor (UTA) y la Cámara Empresaria de Transporte Turístico y Oferta Libre (CETTOL), (Convenio Colectivo de Trabajo para la actividad de los Servicios Especiales, Urbanos, Interurbanos, Charters y Turismo).

Los niveles salariales del convenio UTA mencionado para los Servicios de Transporte para el Turismo son similares a los niveles de los conductores de servicios regulares. A través de las entrevistas realizadas se verificó que el grado de cumplimiento del convenio para los conductores de estos servicios de línea enmarcados en la normativa de Turismo podría ser bajo, si bien los controles no permiten conocer la real situación, pero además hay una fuerte presencia de transportistas autónomos, condición que, según han declarado los operadores consultados, es necesaria para hacer rentables a la operatoria.

En junio de 2018, la Secretaría de Gestión del Transporte, del Ministerio de Transporte de la Nación, autorizó a las empresas de servicio público interurbano a operar con un solo conductor en distancias de hasta 200 kilómetros (Resolución SGT 115/ 2018). Esta resolución equipararía a las empresas de servicios regulares con combis ya que sus servicios siempre se han prestado con un único conductor; pero solo rige para distancias muy cortas interurbanas.

Con el correr de los años y la crisis política, económica y social que atravesó Argentina en el año 2001, se planteó en emergencia el sistema de transporte interurbano que impulsó el cierre de registros para servicios turísticos. La Resolución ST 127 del año 2001 estableció la suspensión de recepción de solicitudes de inscripción, renovación y modificación de inscripciones de los servicios para el Turismo en el Registro Nacional del Transporte de Pasajeros por Automotor y de Servicios de Oferta Libre en el Registro Nacional del Transporte de Pasajeros por Automotor de Carácter Urbano y Suburbano. La norma consideraba pertinente suspender el otorgamiento de nuevos permisos hasta que se modificara el marco regulatorio, manteniendo la situación existente y evitando la incorporación de nuevos prestadores. Excepcionalmente, en el año 2009 se abrió temporalmente el registro por 90 días, habilitando la inscripción de aproximadamente 1.000 operadores, según lo informado por funcionarios de la CNRT. El registro fue nuevamente abierto mediante la Resolución SGT 73/2017.

Este cierre del registro no fue menor en la conformación del perfil empresario de los servicios de combis ya que la única forma de ingresar al sector es ofreciendo servicios a un operador establecido. Si bien existen algunos transportistas dueños de la totalidad de los equipos con los que opera (que nunca son un número que supere a la docena de unidades) muchos otros actúan como agentes de viaje: cuentan con el permiso de Servicios de Transporte para el Turismo, disponen de muy pocas (o ninguna) unidades propias y contratan a otros dueños de combis habilitadas para que trabajen para ellos (se los denomina fleteros) que ingresan al sector registrando los vehículos mediante un contrato realizado con el responsable del permiso.

Por otro lado, las empresas de servicios regulares no pueden efectuar sus servicios con vehículos tipo combis ya que la legislación vigente, Decreto 2407/2002 y la Resolución 395 de junio de 1989 de la ex-Secretaria de Transporte y Obras Publicas del 
Ex-Ministerio de Obras y Servicios Públicos, estableció que los vehículos deben ser todos chasis carrozados, de manera tal que los vehículos combis, por ejemplo Sprinter (el vehículo característico de las "combis de línea"), no son de la partida para sus servicios regulares. Esta prohibición les impide dedicarse a porciones de mercado de despachos más pequeños, más allá de que es probable que, aun pudiendo, las empresas regulares no optarían por esta posibilidad.

En definitiva, existe una demanda de transporte de pasajeros de mediana distancia interurbana desde localidades de porte medio a otras ciudades de mayor tamaño que operan como centralidades laborales, educativas, sanitarias, culturales, de trámites, etc., y que es cubierta por pequeños transportistas por fuera de la norma establecida pero que, en la práctica, operan en un mercado cuya morfología es de total desregulación económica en cuanto a frecuencias, precios, orígenes y destinos e incluso en la propiedad de los vehículos utilizados.

Luego de este pequeño análisis normativo sectorial, la práctica indica, de acuerdo a las entrevistas realizadas, que la presencia de servicios de combis haciendo línea sin permiso legal explícito sigue totalmente en expansión, cabe preguntarse cómo es que tal cosa sucede sin afectaciones a los viajes, condición central para que estos servicios se desarrollen. La respuesta es la característica en situaciones como esta: operan, de alguna manera, con un permiso implícito de las autoridades; hecho que fue constatado en todas las entrevistas realizadas con transportistas y funcionarios. Como parte del relevamiento desde técnicas de observación en trabajos de campo efectuados en la zona de Alto Palermo ${ }^{9}$, se reconocieron inspectores de la CNRT inspeccionando estos servicios pero solo en lo referente a la habilitación de las unidades y a la licencia de los conductores, obligaciones que todas las unidades y conductores cumplían. Sin embargo, más allá de este consentimiento implícito por parte de las autoridades, la falta de normativa específica no es la respuesta que debiera dar el Estado.

\section{El servicio de combis interurbanas de línea}

El fenómeno de las combis de línea contiene diversas características que conforman un patrón particular de desplazamiento en las cortas distancias interurbanas. El trabajo caracteriza el fenómeno en función de la comprensión del origen del servicio, sus transformaciones y adaptaciones; cómo se especializa en determinados territorios (distancias recorridas, tipos de ciudades que une, duraciones, frecuencias, atención de la demanda, forma de operar); los vehículos utilizados (capacidad, confort) que inciden en los tipos de viaje; cómo compiten con modos de transporte y qué perfiles de usuarios se configuran. La caracterización de estas distintas dimensiones nos acerca a comprender el fenómeno de manera más global.

\section{El origen del servicio}

El servicio de combis de línea en la larga distancia de Jurisdicción Nacional comenzó a visualizarse con esta operatoria durante la década del $90^{`}$ del siglo pasado y, con el paso del tiempo, fue cobrando relevancia en el sistema interurbano hasta alcanzar porciones muy importantes de la demanda de viajes en algunos corredores. 
Las indagaciones realizadas, básicamente a través de entrevistas, hacen suponer que las primeras camadas de estos servicios fueron una paulatina transformación desde típicos servicios de transporte para el turismo (tours de compras con contingentes plenamente cerrados o transporte turístico de pequeños grupos de pasajeros, por ejemplo) o incluso transporte escolar, hacia transporte de línea regular desde las mismas localidades de origen de esos viajes de turismo de compras o de servicios escolares hacia ciudades más grandes, atractoras de los viajes (empresarios de combis, entrevista 2019).

Estos operadores se fueron consolidando como oferentes en sus localidades de origen y algunos de ellos ampliaron su oferta a otras ciudades cercanas combinando, a veces, los servicios hacia la localidad principal de destino. Su trato personal con la demanda los hizo, y hace, muy permeables a sugerencias y reclamos de la demanda. Consecuencia de ello ha sido el ofrecer servicios desde la puerta de la casa (entrevistas a usuarios y empresarios, 2019) de los pasajeros en las ciudades de origen, el uso de unidades de mayor capacidad en los días de mayor demanda (como algunos fines de semana), la forma de pago de los viajes o la flexibilidad en la fijación de horarios de los viajes. Pero además, le otorgó a estos servicios un halo de "seguridad" 10 del que no disponen los servicios regulares en ómnibus, donde los pasajeros son más anónimos (entrevistas a usuarios, 2019).

En determinadas ciudades, como Chivilcoy (distante a unos $170 \mathrm{~km}$ de Buenos Aires), por ejemplo, durante los últimos años la demanda aumentó en sintonía con el crecimiento poblacional de la mancha urbana. Paralelamente, la oferta de servicios se incrementó como también la duración de los recorridos al interior de la ciudad. Esto provocó que algunos pasajeros prefirieran acceder a los servicios en puntos estratégicos de la ciudad para ahorrar tiempo de viaje frente a la posibilidad de que los recojan por sus hogares. El reconocimiento de las distintas preferencias de la demanda, identificadas a partir de sondeos de los empresarios, amplió la diversidad de tipos de servicios: puerta a puerta o por puntos estratégicos (entrevistas a empresarios, 2019).

El origen empresarial estuvo dado por una readaptación de los servicios frente a falencias o imposibilidades de los servicios de ómnibus regulares ofreciendo mejores condiciones a los pasajeros y captando, de esta forma, nuevas camadas de viajeros. Las entrevistas tanto a empresarios como a usuarios, permitieron reconocer que con el correr de los años los servicios de combis experimentaron una curva de aprendizaje que les permitió mejorar progresivamente el servicio adaptándose a los contextos e ir haciéndose un lugar en el mercado.

Resulta interesante analizar cuáles han sido las falencias y/o imposibilidades de los servicios regulares de ómnibus y por qué las combis no se han desarrollado y consolidado en todas las ciudades medianas ni en todos los corredores. En los casos relevados, la precondición para el surgimiento de estos servicios ha sido la existencia de bajas frecuencias de los servicios regulares (CNRT, 2016). La cantidad de frecuencias de los servicios regulares están establecidas en sus permisos habilitantes si bien las empresas tienen un margen para variarlo, en más o en menos. Pero la cantidad efectiva de servicios se relaciona con la demanda efectiva dirigida a los servicios regulares y si esta no es lo suficiente para hacer rentables los viajes, las frecuencias, entonces, tenderán a disminuir. Y viceversa. Una demanda baja podría no hacer atractivo el mantenimiento de varias frecuencias semanales en unidades con una capacidad de 50 / 60 asientos pero tal vez sí para una oferta en unidades de 18 / 20 asientos. 
Fue, y es, esa baja frecuencia de los servicios regulares la que permite el establecimiento de combis cubriendo esa demanda de despachos pequeños y, una vez consolidado el servicio, es muy difícil, cuando no imposible, la remisión de la actividad. Por ejemplo, mientras que el corredor de la ruta nacional 205 presenta una fuerte operación de servicios de combis en las ciudades de Saladillo, Roque Pérez, 25 de Mayo, etc. (CELADI, 2016), las ciudades a la vera de la ruta nacional 7, en las distancias a Buenos Aires en donde estos servicios se especializan, como Azul u Olavarría, nunca han podido hacer "pie" ya que la oferta de servicios regulares es lo suficientemente amplia como para impedir, hasta ahora, su surgimiento (entrevista a empresarios, 2019).

\section{Especialización geográfica de los servicios de combis}

Para este trabajo la noción de especialidad geográfica remite un tipo de servicio prestado en determinado recorte territorial, entre ciudades con características específicas y en distancias interurbanas relativamente cortas. Tal como se revisó en el apartado "Marco de interpretación para el análisis de transporte interurbano en las cortas distancias", los servicios se inscriben en un contexto territorial motivado por la relación establecida entre ciudades de distintas jerarquías (chicas/medias y metropolitanas), conectadas a través de redes viales que facilitan la circulación mediante la promoción de mayor velocidad. Las redes articulan escalas, seleccionan territorios solidarizando elementos y excluyendo a otros a partir de la selección de nodos y canales (Santos, 2000; Blanco, 2015). En este marco, las combis parecieran ofrecerse como el modo público que mejor se adapta a los imperativos de la circulación. Las características del servicio (duraciones, frecuencias, atención de la demanda, forma de operar) se ajustan mejor que otros servicios de transporte (ómnibus de larga distancia, trenes) a las necesidades de desplazamiento de la demanda entre esos tramos. Como consecuencia, ejercen competencia con otros modos prestados en los mismos trayectos.

El fenómeno de las combis de línea es reconocible en varias provincias, en especial en el norte del país, como también se observan ciudades que resultan ser centro de atracción de viajes regulares en combis: Área Metropolitana de Buenos Aires, Bahía Blanca, Córdoba, San Salvador de Jujuy, Corrientes, entre otras muchas. Su alcance territorial es del orden de los $200 \mathrm{~km}$ aunque en Buenos Aires esa distancia media resulta un poco mayor. En ciudades del norte, como Salta y Jujuy, entre los vehículos de larga distancia se observan combis y taxis que conectan a estas ciudades capitales con otras localidades de la región (Purmamarca, Tilcara, Humahuaca). Este caso plantea grandes tensiones a los empresarios de ómnibus de servicios regulares de larga distancia ya que, según lo expresado por ellos, estos servicios le han quitado cerca del $40 \%$ de la demanda (entrevistas a técnicos de la Dirección Nacional de Planificación de Transporte Interurbano e Internacional de Pasajeros, 2016).

El estudio de CELADI (2016) en la provincia de Buenos Aires permitió reconocer que los servicios de combis se acentúan entre ciudades de porte chico con medianas/ grandes. El estudio indica que las ciudades del interior de la provincia de Buenos Aires, que realizan viajes a ciudades de gran porte, tienen entre 10.900 habitantes (las más chicas) y 63.200 (las de mayor tamaño). En los siguientes mapas (Figuras 3 y 4 ) se muestran, esquemáticamente, las áreas de influencia de varias ciudades del país. Complementariamente, se observa desde el cuadro 1 los orígenes y destinos, distancias, frecuencia semanal ida y vuelta, ocupación vehicular y pasajeros por semana de los distintos corredores estudiados (RN5, RN9 y RN205). 


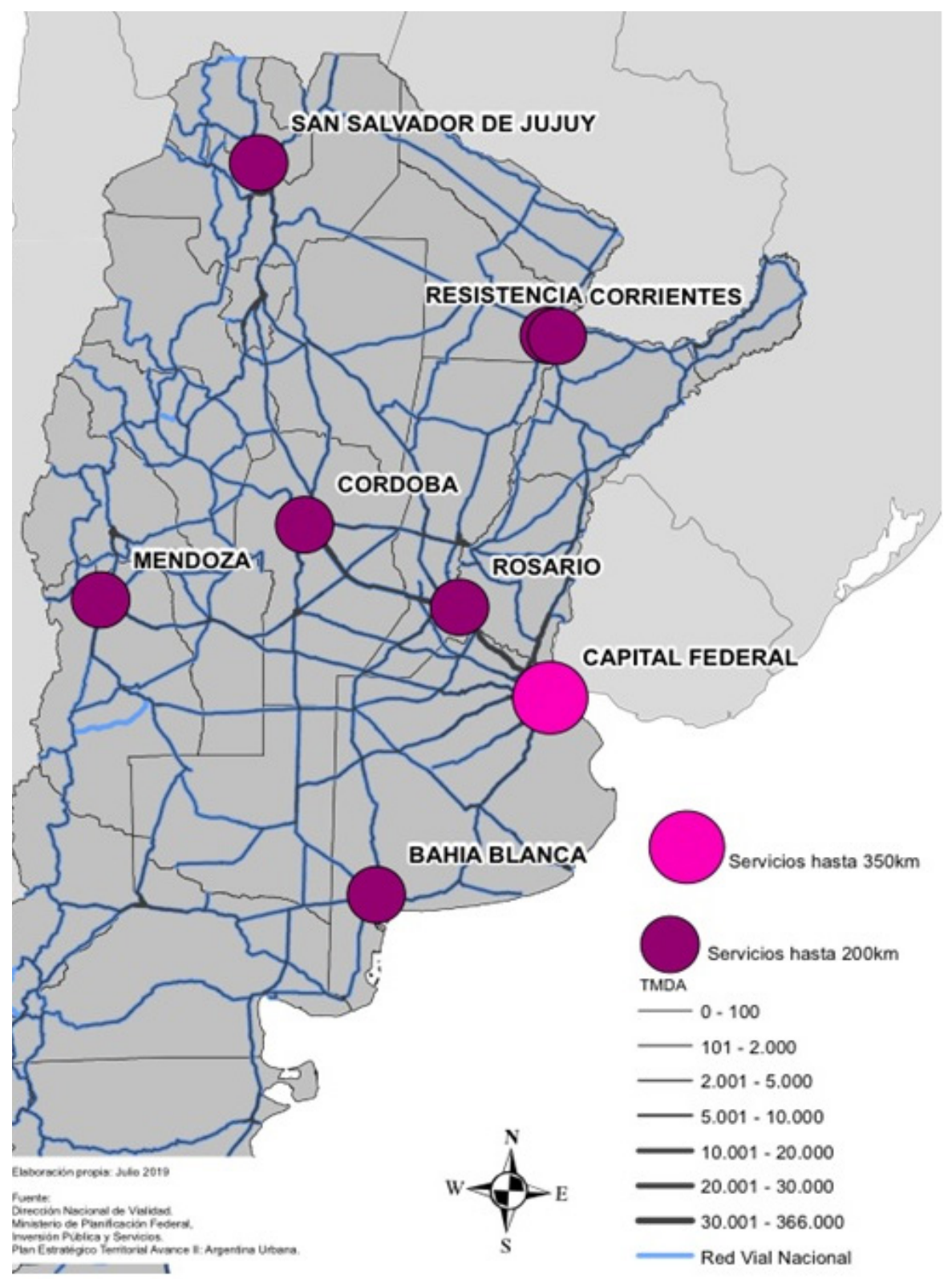

Figura 3. Distancias medias de los servicios de combis en Argentina. Fuente: elaboración propia, basado en datos provistos por la Dirección de Transporte Interurbano e Internacional de Pasajeros, recolectados en el marco de los talleres provinciales, 2019. 


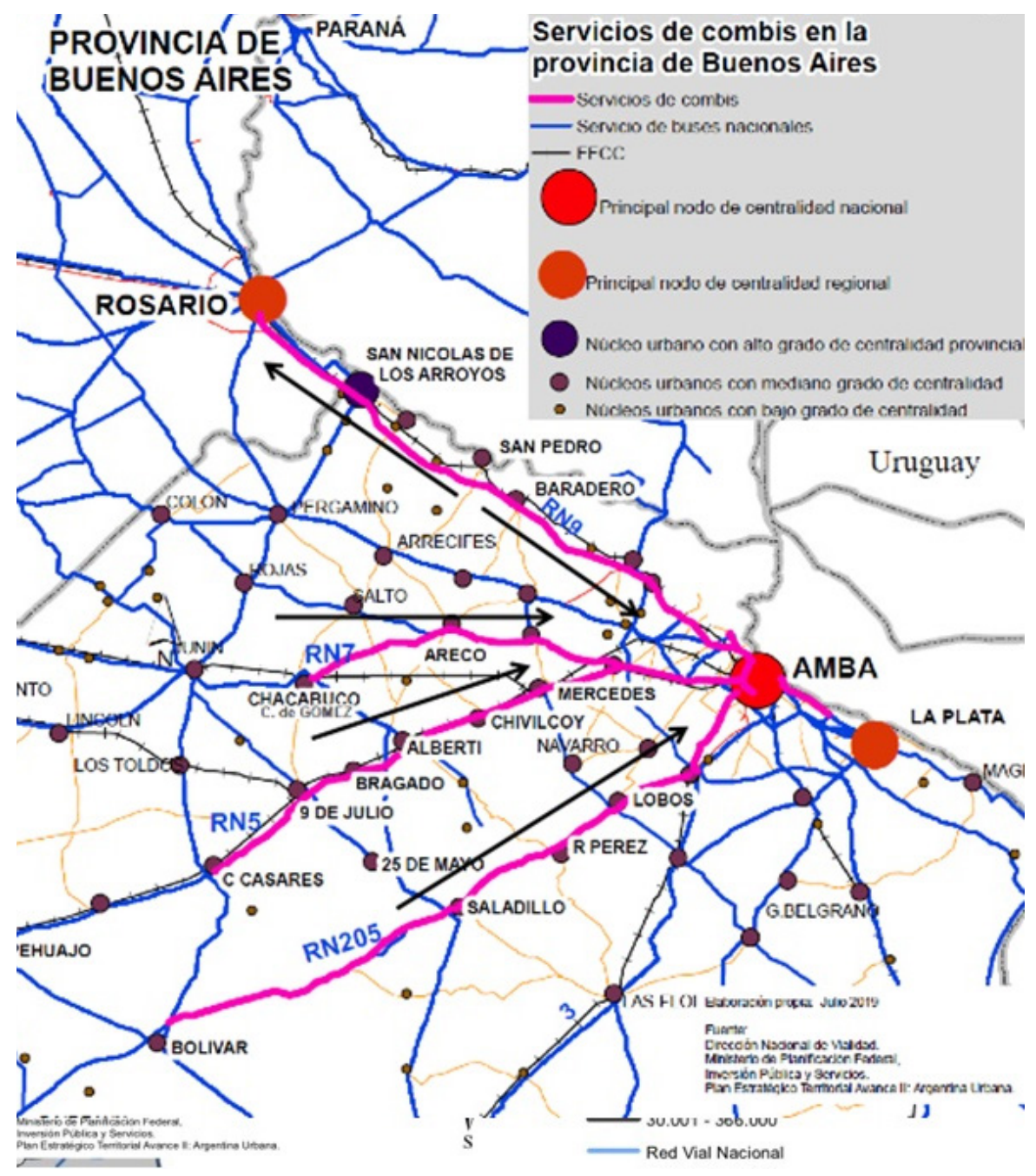

Figura 4. Servicios de combis en la provincia de Buenos Aires. Fuente: elaboración propia en base a datos de la DNPTIeIP, 2019.

Cuadro 1. Comparación de servicios por corredor. Fuente: elaboración propia en base a datos CELADI (2016).

\begin{tabular}{|c|c|c|c|c|c|c|c|}
\hline Corredor & \begin{tabular}{|l} 
Localidad \\
origen
\end{tabular} & \begin{tabular}{|l} 
Localidad \\
destino
\end{tabular} & Distancia & \begin{tabular}{|c|} 
Cantidad de \\
habitantes, \\
localidad de \\
origen
\end{tabular} & $\begin{array}{c}\text { Frecuencia } \\
\text { semanal } \\
\text { (ida y } \\
\text { vuelta) }\end{array}$ & $\begin{array}{c}\text { Ocupación } \\
\text { media por } \\
\text { vehículo }\end{array}$ & $\begin{array}{c}\text { Pasajeros } \\
\text { por } \\
\text { semana }\end{array}$ \\
\hline \multirow[t]{7}{*}{ RNs } & Mercedes & CABA & 94 & 63.200 & 100 & 17 & 1.700 \\
\hline & Chivilcoy & CABA & 167 & 59.000 & 304 & 17 & 5.168 \\
\hline & Bragado & CABA & 219 & 32.800 & 138 & 17 & 2.346 \\
\hline & 9 de Julio & CABA & 260 & 47.000 & 44 & 17 & 748 \\
\hline & Chivilcoy & La Plata & 202 & 59.000 & 12 & 17 & 204 \\
\hline & Bragado & La Plata & 251 & 32.800 & 12 & 17 & 204 \\
\hline & 9 de Julio & La Plata & 310 & 47.000 & 14 & 17 & 238 \\
\hline \multirow[t]{9}{*}{$\mathrm{RN}_{205}$} & Cañuelas & CABA & 63 & 32.000 & 572 & 17 & 9724 \\
\hline & Lobos & CABA & 95 & 31.200 & 510 & 17 & 8.670 \\
\hline & Roque Pérez & CABA & 125 & 10.900 & 102 & 17 & 1.734 \\
\hline & \begin{tabular}{|l|} 
Saladillo \\
\end{tabular} & CABA & 184 & 23.300 & 70 & 17 & 1.190 \\
\hline & 25 de Mayo & CABA & 205 & 36.000 & 132 & 17 & 2.244 \\
\hline & Gral. Alvear & CABA & 239 & 29.000 & 38 & 17 & 646 \\
\hline & \begin{tabular}{|l|} 
Bolívar \\
\end{tabular} & CABA & 334 & 26.000 & 30 & 17 & 510 \\
\hline & 25 de Mayo & La Plata & 244 & 36.000 & 32 & 17 & 544 \\
\hline & Saladillo & La Plata & 203 & 23.300 & 46 & 17 & 782 \\
\hline \multirow[t]{4}{*}{$\mathrm{RN} 9$} & San Pedro & CABA & 190 & 47.500 & 106 & 17 & 1.802 \\
\hline & Baradero & CABA & 176 & 40.000 & 38 & 17 & 646 \\
\hline & San Pedro & Rosario & 157 & 47.500 & 40 & 17 & 680 \\
\hline & Baradero & Rosario & 178 & 40.000 & 16 & 17 & 272 \\
\hline
\end{tabular}


El comportamiento de los viajes se corresponde con la atracción que generan las ciudades de gran porte alentado por los servicios que ofrecen: educación universitaria, salud, cultura, sociabilidad, trámites, etc., no provistos por las ciudades de porte chico / mediano. Esta dinámica entre las ciudades revisadas se ve alimentada por la presencia de corredores de circulación de alta velocidad que disminuyen los tiempos de viaje.

En otras palabras, la especificidad del servicio se asocia a las distancias promedio, al tipo de ciudades que une (porte chico con ciudades grandes), flexibilidad del servicio, que en definitiva resultan más atractivas para los usuarios y más competitivas en relación al resto de las ofertas en ese tipo de distancias. Es en este sentido que el trabajo considera que el servicio de combis es una oferta con "especialidad geográfica".

\section{Competencia de las combis con otros modos de transporte11}

La competencia de las combis está dada, básicamente, con los servicios regulares de ómnibus y los automóviles particulares. También, en algunos pares orígen y destino hay servicios ferroviarios, pero las pocas frecuencias y la falta de confiabilidad que brindan hacen del ferrocarril una alternativa más lejana. No compiten con el transporte aéreo puesto que la distancia media de las combis es muy inferior al modo aéreo. En el gráfico siguiente se muestran las distancias medias de cada modo de transporte en el territorio argentino.

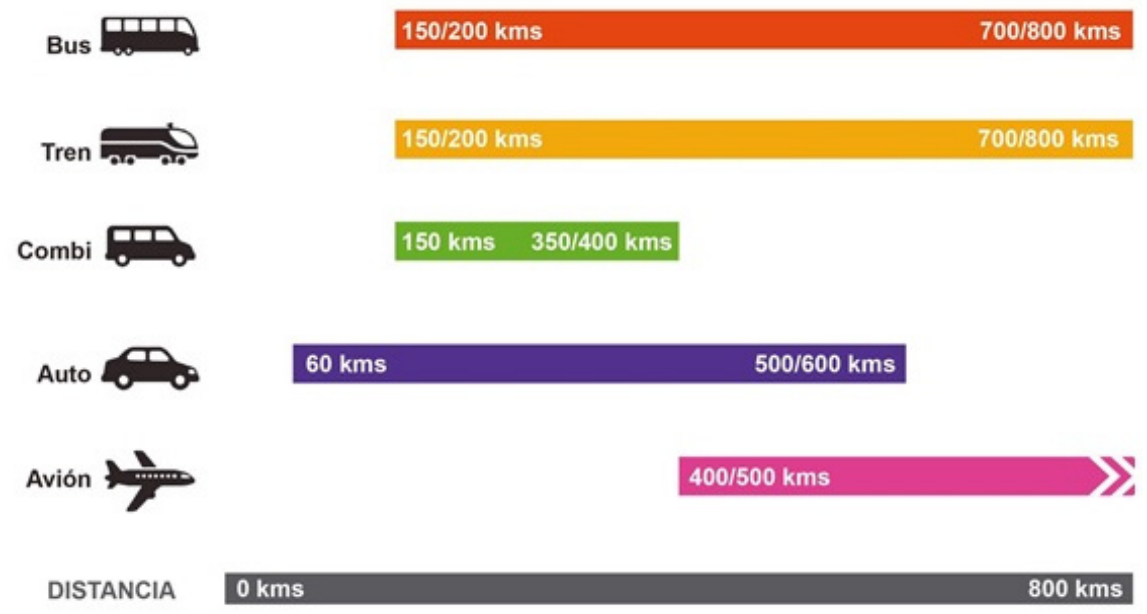

Figura 5. Distancias medias por modo. Fuente: elaboración propia, 2019.

Desde la perspectiva de los empresarios de ómnibus de servicios regulares, la competencia con las combis está promovida por los menores costos impositivos y laborales de esta modalidad de servicios que le quitan pasajes al ómnibus regular (Ferraresi, 2012) ${ }^{12}$.

11 En el Anexo Metodológico se muestran distribuciones modales para varios pares origen-destino estimados en el marco de este estudio.

12 Dado que el convenio UTA establece niveles salariales semejantes en las dos ramas de actividad involucradas (servicios de ómnibus regulares y servicios de transporte para el turismo), ese no debería ser un factor de asimetrías salvo que ocurrieran dos cosas: i) que la proporción de choferes asalariados en las combis fuera muy pequeño respecto al conjunto de conductores; de acuerdo a lo señalado por transportistas de combis entrevistados, el sector muestra una fuerte presencia de transportistas autónomos con poco trabajo asalariado o ii) que, existiendo mucho trabajo asalariado, el convenio no se cumpliera, con lo que los controles de los organismos de contralor mostrarían sus falencias. 
El escenario de información estadística y de registros de combis es incompleto, ya que no se tiene identificado el universo de los vehículos y empresas que operan cotidianamente en la oferta de servicios diarios entre ciudades. Las estadísticas suelen agrupar los diversos usos que se hacen de las combis (servicios de línea, turismo, servicios urbanos) dificultando la distinción entre los mismos. Como consecuencia, no se tiene un conocimiento global y exclusivo de este tipo de modalidad de servicios de línea prestado por las combis acorde al uso concreto.

Tal como se mencionó anteriormente a partir de información obtenida y revisada (ver Anexo) se obtuvieron los siguientes resultados:

" Hay corredores con fuerte presencia de servicios Combis de línea, por ejemplo el corredor de la ruta nacional № 205, y otros donde son inexistentes como en la ruta nacional No 3 en las ciudades de Las Flores, Azul y Olavarría.

»En los casos en donde operan las combis, su tráfico se encuentra, en la casi totalidad de los casos, por encima del de los servicios regulares de línea en ómnibus. Las combis explican entre un $20 \%$ y un $30 \%$ del tráfico total en los pares origen y destino analizados, lo cual marca su aceptación por parte de la población usuaria y de la normalidad con que se prestan estos servicios.

» En todos estos pares origen y destino, el grueso del tráfico se explica por el uso del automóvil particular en una proporción que ronda las dos terceras partes del total de tráfico.

"Los precios de los servicios de combis se encuentran muy cercanos a los de los servicios regulares de ómnibus, a veces por encima y otras veces (las menos) por debajo.

\section{Usos de la población ¿̇por qué lo eligen?}

A partir de sondeo en puntos de ascenso a los servicios de combis y entrevistas se pudieron identificar perfiles y usos que efectúan los usuarios. A grandes rasgos, se distinguen dos grupos diferenciados por motivos de viaje asociados a las actividades desempeñadas en distintos momentos de la semana, cuyos viajes adoptan distintas características (frecuencias, obligaciones y preferencias de uso).

Por un lado, se observa un grupo de pasajeros con hábito de viaje los días hábiles de la semana. Generalmente, este grupo de usuarios reside en ciudades del interior de la provincia de Buenos Aires y viajan a la CABA por motivo trabajo, dado que allí se encuentran sus actividades laborales. Este tipo de viajes implican un nivel de regularidad mayor por la obligatoriedad respecto de otro tipo de viajes. Las personas deben viajar desde las ciudades chicas, como mínimo, una vez por semana. En el sondeo hubo declaraciones de personas que llegaban a viajar hasta cuatro veces en la semana. El hecho de no tener que manejar es una motivación relevante a la hora de preferir el modo frente al auto particular porque les permite utilizar el tiempo de viaje para otras actividades (trabajo, descanso). Otros motivos de los viajes en días hábiles se asocian a las consultas por temas de salud y a la realización de trámites, cuya frecuencia de viaje es menor.

La elección del modo coincide en las comodidades que ofrece el servicio: búsqueda en la puerta de los hogares, paradas en puntos accesibles dentro de la CABA, confianza en los prestadores del servicio. Las personas mayores de edad prefieren el servicio porque es más confortable viajar en unidades pequeñas y poca presencia de niños, a diferencia del servicio de ómnibus.

Otro grupo de pasajeros se enmarca dentro de los viajes de fin de semana. Estos pasajeros pueden residir en ciudades de la provincia de Buenos Aires como también en la CABA. Los motivos de viaje tienden a ser de carácter más bien social, por 
ejemplo: estudiantes que viajan desde la CABA a visitar a sus familias que residen en el interior, o viceversa (personas que visitan a familiares en la CABA). Otro tipo de viajes los realizan personas que viajan desde el interior con incentivos culturales no accesibles en las respectivas ciudades, o por compras. Estos desplazamientos son menos frecuentes que los mencionados anteriormente; pueden llegar a realizarse aproximadamente una vez al mes. La elección por sobre el ómnibus, al igual que los pasajeros frecuentes, responde a la accesibilidad al servicio (ascenso/descenso en la puerta de los hogares y ascenso/descenso en la CABA en puntos de mayor comodidad para la población viajera).

El hecho de que la Estación Terminal de ómnibus de Retiro, en CABA, no sea el punto de ascenso y descenso de los viajes en combis, es un factor relevante ya que los pasajeros se sienten inseguros en la zona de Retiro por temor a los robos. También prefieren las combis porque el tiempo de viaje es menor. Frente a la opción de viajar en auto particular, algunas personas lo prefieren porque representa menor tiempo de viaje y mayor confort. En estos casos es frecuente la práctica de compartir el viaje con personas conocidas.

Pueden darse situaciones particulares que promueven perfiles de usuarios específicos. Por ejemplo, a partir de las entrevistas a empresarios se dio cuenta que la presencia de la cárcel de Mercedes atrae viajes frecuentes de los familiares de los presos que viajan a visitarlos en ómnibus y genera una demanda paralela de usuarios de combis que no quieren compartir los viajes con los familiares de los carcelarios; o iglesias que atraen viajes con motivo religioso. Es decir, que los perfiles delineados anteriormente, son generales y pueden estar conformados por otros grupos socioculturales que se ven atraídos por motivos específicos que pueden satisfacerse en ciudades puntuales.

En todos los casos, los pasajeros coinciden en que los aspectos negativos de los servicios de combis se asocian a las dificultades de conseguir pasajes sobre la fecha y hora de viaje, ya que se agota la disponibilidad de asientos. Otra incomodidad remarcada es el tiempo de espera en el que incurren cuando el servicio hace la repartición de personas cuando ingresan a las respectivas ciudades de la provincia. Como también hay quienes cuestionan que se extendió el tiempo de viaje por congestión en la entrada a la CABA.

Paralelamente, los oferentes de servicios de combis son flexibles ante los cambios de comportamiento de la demanda, es decir que crean nuevas ofertas acordes a las nuevas necesidades emergentes. Esto es posible a partir de la aplicación herramientas como encuestas (en algunos casos), que permiten conocer preferencias de los usuarios y como consecuencia nuevas oportunidades de negocio que flexibilizan la oferta. Por ejemplo, unos años atrás era habitual en los viajes entre Chivilcoy y CABA realizar una parada intermedia en una estación de servicio. Esta práctica fue modificada a partir de sondeos a los pasajeros que preferían que el viaje sea más corto. En otros casos, dado el incremento de tiempo en la búsqueda de pasajeros por los hogares, se ofreció un servicio paralelo prestado desde puntos estratégicos de la ciudad del interior.

\section{Conclusiones}

A partir del proceso de trabajo fue posible visibilizar un fenómeno existente en el orden de las prácticas de movilidad interurbana que permanece oculto en el ámbito de la gestión y planificación del transporte. Tal como se pudo revisar, el uso de combis interurbanas contiene patrones de comportamiento que las diferencian y destacan respecto de otras ofertas modales abocadas a los viajes cortos interurbanos. 
Resumidamente y de acuerdo al caso analizado, el servicio se caracteriza por su origen temporal relativamente reciente respecto a otros modos (década de los años 90), con especialización en distancias entre 100 a 150 y 300 a $350 \mathrm{~km}$, uniendo ciudades de porte chico/medio con ciudades grandes. Los servicios mantienen altas frecuencias diarias, con amplitud horaria, en corredores de alto tránsito vehicular. El conjunto de características del servicio le otorga una mayor adaptación territorial respecto al resto de las ofertas modales en las cortas distancias. Los vehículos tienen una capacidad menor a las del ómnibus, de confort medio, con baja capacidad para llevar equipaje, lo cual incide en tipos de viaje conforme a las distancias cortas interurbanas y acordes a los perfiles de usuarios que demandan el servicio. La demanda de transporte de pasajeros desde localidades de porte medio tiende a recurrir a las ciudades de mayor tamaño en búsqueda actividades laborales, educación superior/universitaria, servicios de salud, culturales, trámites, etc., bajo el requisito de viajar en menor tiempo.

Tal como se revisó, los servicios se inscriben en un contexto territorial motivado por la relación establecida entre ciudades de distintas jerarquías y conectadas a través de redes viales que facilitan la circulación mediante la promoción de mayor velocidad. Asimismo, articulan escalas y seleccionan territorios solidarizando elementos y excluyendo a otros a partir de la selección de nodos y canales (Santos, 2006; Blanco, 2015). Este escenario vinculado con el fenómeno particular de las combis, pareciera ser el modo que se adapta mejor a los imperativos de la circulación, ofreciendo mayor velocidad comercial, oferta horaria, accesibilidad entre escalas (tanto interurbana como dentro de las ciudades). Adaptándose mejor, a su vez, a los nuevos contextos y poniendo en tensión a la tradicional oferta de ómnibus de larga distancia, la cual debe recurrir a nuevas estrategias para no perder pasajeros.

Desde la perspectiva específica de la oferta, los servicios están cubiertos por pequeños transportistas que prestan servicio por fuera de la norma establecida pero que, en la práctica, operan en un mercado cuya morfología es de total desregulación económica en cuanto a frecuencias, precios, orígenes y destinos e incluso en la propiedad de los vehículos utilizados. La oferta de combis cumple una función en la movilidad interurbana ya que ofrece una alternativa satisfactoria a la demanda de viajes interurbanos de corto alcance.

Paralelamente, estos hallazgos dejan a la luz tensiones con aquellos actores que pres$\tan$ otros servicios interurbanos y que compiten en los mismos corredores, como también con aquellos organismos que gestionan y planifican el transporte de esas jurisdicciones.

En primer lugar, y de modo más visible la presencia de los servicios de combis ejerce competencia a los servicios de ómnibus de larga distancia que prestan servicio en distancias cortas en mismos corredores. El surgimiento de los servicios se asocia a la existencia de bajas frecuencias de los servicios regulares, preestablecidas en sus permisos habilitantes y con poco margen para variarlo. Fue, y es, esa baja frecuencia de los servicios regulares la que permite el establecimiento de combis cubriendo esa demanda de despachos pequeños. Pero una vez consolidado el servicio de Combis es muy difícil, cuando no imposible, la remisión de la actividad.

Paralelamente, la permanente violación de la modalidad autorizada en que se prestan los servicios expresa una falta de entendimiento del fenómeno desde la autoridad pública que implícitamente habilita su participación sin generar reglas claras. Esto se verifica en la presencia de servicios que hacen línea sin permiso legal explícito, lo cual cuestiona qué tipo de marco normativo es el que corresponde que tengan los servicios de combis de larga distancia. Las combis al estar bajo la figura de turismo y realizar una actividad más semejante a la del servicio público, no tienen existencia jurídica acorde a su práctica. Y los servicios dados por estas combis, donde el vehículo emerge como el equipo adecuado, no pueden ser brindados por los operadores de servicios públicos 
porque la normativa les impide operar con estos vehículos. La opinión empresarial aspira a la igualdad en las condiciones de competencia entre empresarios, los cuales deben operar bajo un mismo marco normativo, con igualdad de condiciones de cumplimiento. En este sentido, también coinciden que la normativa debe ser revisada a título de que convivan los sistemas.

Entre las propuestas para las modificaciones de la normativa planteadas desde los prestadores de servicios de ómnibus, se encuentran las que se refieren al tipo de vehículo acorde para brindar servicios de mediana distancia. Una de las posibles legislaciones aplicables al transporte regular de pasajeros de larga distancia sería el permitir operar a las empresas con vehículos pequeños y con gran capilaridad en la primera y la última milla. Sería relevante que la normativa permita y regule este tipo de vehículos para los servicios públicos interurbanos en distancias relativamente cortas. Este marco legal permitiría, entre otras cosas, brindar mayor seguridad respecto a cómo debe operar los respectivos servicios a los fines de cuidar la integridad de los pasajeros.

Por otro lado, la falta de identidad en el marco de las normas vigentes también interroga respecto a qué identidad debe adquirir el fenómeno en la esfera de la planificación del transporte, es decir, qué lugar se le debería dar a la combi en el sistema interurbano de transporte. Las decisiones tomadas para el largo plazo pueden establecer una postura general con impacto en otros ámbitos como son el marco normativo, la gestión o el control, entre otras cosas. Opiniones de diversos funcionarios revisados desde las entrevistas, coinciden en que tanto la oferta de servicios de ómnibus como la de combis, si bien realizan los mismos recorridos, son distintos tipos de oferta y pueden convivir en el sistema en la medida que oferten distintos servicios y se complementen. Una de las ideas postuladas es que los servicios regulares de larga distancia en ómnibus centren sus recorridos troncales entre ciudades de gran porte, y donde en los extremos de los recorridos se armen hubs que combinen con las combis para las distribuciones hacia ciudades de menor escala.

En materia normativa, las ideas planteadas para salir del estado de situación actual fueron: modificar ciertas regulaciones permitiendo a las operadoras establecidas de servicios regulares el operar con vehículos $\mathrm{M} 2^{13}$, que incluye a las combis; ó establecer una categoría de servicios regulares de hasta $350 \mathrm{~km}$ (o $400 \mathrm{~km}$ ) de extensión en donde se pueda operar haciendo línea, en un mercado absolutamente desregulado en materia económica (tal como casi hoy se registra).

Más allá de las diversas opiniones que promueve el tema, la relevancia del trabajo está dada por la visibilización del mismo a partir de la articulación de distintas técnicas de estudio cuantitativas como cualitativas, no comúnmente utilizadas desde las áreas de gestión y planificación del transporte. Dichas técnicas revelaron movilidades no registradas (Gutiérrez, 2012) por los organismos oficiales y que forman parte de las prácticas de movilidad interurbana cotidianas en las cortas distancias.

\section{Anexo metodológico}

\section{Estimación de la distribución modal en algunos pares OD seleccionados}

Los criterios adoptados para poder estimar la demanda en algunos pares Origen Destino $(\mathrm{O}-\mathrm{D})$ fueron los siguientes: 
» A todas las empresas habilitadas en el Registro de Operadores de la CNRT en la categoría "Turismo" y con al menos algunas unidades de menos de 20 asientos se las buscó en Internet para ver si ofrecían servicios regulares de transporte. Esa fue una condición de borde: si no tenían publicitados sus horarios no se consideraba que operaran "línea".

Un ejemplo de horarios publicados en Internet por las empresas de combis (minúsculas) de línea es el que se muestra a continuación.

\begin{tabular}{|c|c|c|c|c|c|c|c|}
\hline \multicolumn{8}{|c|}{$\begin{array}{l}\text { SANTORINI } \\
\text { HORARIOS DE COMBIS }\end{array}$} \\
\hline \multicolumn{8}{|c|}{ Importante: Menores de 18 ahios no pueden viajar sin autorización } \\
\hline Vaje & Lunes & Martes & Miercoles & jueves & Viernes & Sthando & Domingo \\
\hline $\begin{array}{l}\text { CHIVILCOY } \\
\text { - BUENOS } \\
\text { AIRES }\end{array}$ & $\begin{array}{c}04: 50 / 06: 00 / \\
07: 00 / 03: 15 / \\
09: 30 / 13: 00 / \\
15: 30 / 18: 00\end{array}$ & $\begin{array}{c}04: 50 / 06: 00 / \\
07: 00 / 08: 15 / \\
09: 30 / 13: 00 / \\
15: 30 / 18: 00\end{array}$ & $\begin{array}{c}04: 50 / 06: 00 / \\
07.00 / 08: 15 / \\
09: 30 / 13: 00 / \\
15: 30 / 18: 00\end{array}$ & $\begin{array}{c}04: 50 / 06: 00 / \\
07: 00 / 08: 15 / \\
09: 30 / 13: 00 / \\
15: 30 / 15: 00\end{array}$ & $\begin{array}{c}04: 50 / 06: 00 / 07: 00 / \\
08: 15 / 09: 30 / 11: 00 / \\
13: 00 / 15: 30 / 16: 00 / \\
17: 00 / 18: 00 / 19: 00\end{array}$ & $\begin{array}{l}06: 00 / \\
08: 00 / \\
10: 30 / \\
13.00 / \\
15: 30 / \\
18: 00\end{array}$ & $\begin{array}{c}08: 00 / 10: 30 / \\
14: 30 / 17: 00 / \\
18: 00 / 19: 00 / \\
20: 00 / 21: 00\end{array}$ \\
\hline $\begin{array}{l}\text { BUENOS } \\
\text { AIRES - } \\
\text { CHIVICOY }\end{array}$ & $\begin{array}{l}07: 45 / 10: 00 / \\
11: 30 / 13: 30 / \\
15: 30 / 17: 00 / \\
19: 30 / 21: 00\end{array}$ & $\begin{array}{l}07: 45 / 10: 00 / \\
11: 30 / 13: 30 / \\
15: 30 / 17: 00 / \\
19: 30 / 21: 00\end{array}$ & $\begin{array}{l}07: 45 / 10: 00 / \\
11: 30 / 13: 30 / \\
15: 30 / 17: 00 / \\
19: 30 / 21: 00\end{array}$ & $\begin{array}{l}07: 45 / 10: 00 / \\
11: 30 / 13: 30 / \\
15: 30 / 17: 00 / \\
19: 30 / 21: 00\end{array}$ & $\begin{array}{c}07: 45 / 10: 00 / 11: 30 / \\
13: 30 / 15: 30 / 17: 00 / \\
18: 00 / 19: 30 / 20: 30 / \\
21: 00 / 22: 00\end{array}$ & $\begin{array}{c}09: 30 / \\
11: 00 / \\
14: 00 / \\
16: 30 / \\
18: 30 / \\
21: 00\end{array}$ & $\begin{array}{c}11: 00 / 15: 00 / \\
18: 30 / 20: 30 / \\
21: 30 / 22: 30 / \\
23: 30\end{array}$ \\
\hline $\begin{array}{l}\text { BRACADO } \\
\text { - BUENOS } \\
\text { AIRES }\end{array}$ & $\begin{array}{c}04: 15 / 08: 00 / \\
17: 30\end{array}$ & $\begin{array}{c}04: 15 / 08.00 / \\
17: 30\end{array}$ & $\begin{array}{c}0.15 / 08: 00 / \\
17: 30\end{array}$ & $\begin{array}{c}04: 15 / 08: 00 / \\
17: 30\end{array}$ & $\begin{array}{c}04: 15 / 08: 00 / 14: 30 / \\
17: 30 / 20: 00\end{array}$ & $\begin{array}{l}07: 30 / \\
13: 30 / \\
17: 00\end{array}$ & $\begin{array}{c}09.00 / 14: 00 / \\
19.00\end{array}$ \\
\hline $\begin{array}{l}\text { BUENOS } \\
\text { AIRES - } \\
\text { BRACADO }\end{array}$ & $\begin{array}{c}08.30 / 15: 30 / \\
21: 30\end{array}$ & $\begin{array}{c}08: 30 / 15: 30 / \\
21: 30\end{array}$ & $\begin{array}{c}08: 30 / 15: 30 / \\
21: 30\end{array}$ & $\begin{array}{c}08.30 / 15: 30 / \\
21: 30\end{array}$ & $\begin{array}{c}08: 30 / 15: 30 / 19: 00 / \\
21: 30\end{array}$ & $\begin{array}{c}08: 30 / \\
11: 30 / \\
17: 30 / \\
21: 00\end{array}$ & $\begin{array}{c}13.00 / 18: 30 / \\
23.00\end{array}$ \\
\hline $\begin{array}{l}9 \text { DE JUUOO } \\
\text { - EUENOS } \\
\text { AIRES }\end{array}$ & $\begin{array}{c}0.00 / 07: 00 / \\
09: 00 / 14: 00 / \\
17: 30\end{array}$ & $\begin{array}{c}04: 00 / 07: 00 / \\
14: 00\end{array}$ & $\begin{array}{c}04: 00 / 07: 00 / \\
14: 00\end{array}$ & $\begin{array}{c}04: 00 / 07: 00 / \\
14: 00\end{array}$ & $\begin{array}{c}04: 00 / 07: 00 / 09: 00 / \\
14: 00 / 17: 30\end{array}$ & $\begin{array}{l}06.00 ! \\
09.00 / \\
14: 00\end{array}$ & $\begin{array}{c}09: 00 / 14: 00 / \\
18: 00\end{array}$ \\
\hline $\begin{array}{l}\text { BUENOS } \\
\text { AIRES - 9 } \\
\text { DE JULIO }\end{array}$ & $\begin{array}{l}11: 30 / 14: 30 / \\
16: 30 / 19: 00\end{array}$ & $\begin{array}{c}11: 30 / 14: 30 / \\
19: 00\end{array}$ & $\begin{array}{c}11: 30 / 14: 30 / \\
19: 00\end{array}$ & $\begin{array}{c}11: 30 / 14: 30 / \\
19: 00\end{array}$ & $\begin{array}{c}11: 30 / 14: 30 / 16: 30 / \\
19: 00\end{array}$ & $\begin{array}{c}10: 30 / \\
14: 30 / \\
19: 00\end{array}$ & $\begin{array}{c}14: 00 / 19: 00 / \\
22: 30\end{array}$ \\
\hline
\end{tabular}

Figura 6. Tabla de horarios semanales de los servicios de combis de empresa Santorini. Fuente: Santorini turismo.com, 2019.

" Como no en todos los casos fue posible identificar el nombre de fantasía de la empresa prestataria, se buscó en Internet, para muchas ciudades de porte medio, si se ofrecían viajes regulares a ciudades de mayor porte. En general, se buscó ciudades en "hinterlands" de Buenos Aires y Rosario ${ }^{14}$.

» Los pares origen y destino seleccionados diagramaron los siguientes corredores: ruta nacional No 205 (Roque Pérez, Saladillo, 25 de Mayo, Gral. Alvear y Bolívar con Buenos Aires); ruta nacional No 5 (Chivilcoy, Bragado y 9 de Julio con Buenos Aires); ruta nacional No 7 (Carmen de Areco y Chacabuco con Buenos Aires) y la ruta nacional No 9 (San Pedro y Baradero con CABA y Rosario).

"En todos los casos se consultaron los precios por los servicios, los medios de pago y la posibilidad de empezar o culminar el viaje en la ciudad de porte medio en un domicilio dado y no necesariamente por el punto inicial / terminal de los servicios.

"Las frecuencias y precios de los servicios regulares en ómnibus se obtuvieron de agencias de viaje virtuales "Plataforma 10" y "Central de Pasajes".

» Cuando se identificaron los prestatarios se procedió a estimar la demanda a partir de llamadas solicitando pasajes para distintos días y, en el caso de las conexiones con Buenos Aires, yendo a las cabeceras de los alrededores de la plaza Miserere y

14 En el trabajo se buscaron ofertas de estos servicios para muchas ciudades de todo el país pero en este caso, en que se trataba de estimar la demanda, los ejercicios se hicieron únicamente para estas dos ciudades y en viajes "nacionales". 
en la zona del Alto Palermo. Allí se veía el grado de ocupación de los vehículos en las diferentes visitas que se hicieron y con la cantidad de frecuencias se estimó la demanda de ese transportista. Además, se entrevistó a varios pasajeros a fin de indagar sobre sus perfiles de viaje: periodicidad, motivos de viaje, criterios de elección modal, etc.

» Para esos mismos pares O-D se contó con la demanda dirigida a los servicios regulares de ómnibus en información suministrada por la entonces Subsecretaría de Planificación de Transporte Interurbano e Internacional de Pasajeros de la Secretaría de Planificación del Transporte del Ministerio de Transporte de la Nación ${ }^{15}$.

» En la casi totalidad de los casos seleccionados no había servicios ferroviarios de pasajeros o, si los había, sus servicios eran muy poco demandados por la poca confiabilidad que generan o por su discontinua oferta, de manera que no se consideró en la cantidad total de viajes realizados, a los pasajeros ferroviarios.

» Por último, el gran modo transportador es, como en todos los desplazamientos de distancias cortas y medias interurbanas, el automóvil particular. En este caso el camino tomado para la estimación de la demanda fue siguiendo la evolución del Tránsito Medio Diario Anual (TMDA) por tramos y con información primaria de la Encuesta de Viajes y Turismo de los Hogares (EVyTH) del Ministerio de Turismo de la Nación. De todas formas, esta última estimación es la más endeble aunque en la estructura distributiva modal su participación se encontró dentro del rango esperable.

En los cuadros siguientes se muestran la partición modal de los viajes en los pares $\mathrm{O}-\mathrm{D}$ analizados, las frecuencias semanales de los servicios regulares de ómnibus y las de las combis y las tarifas y precios de los servicios de ambos modos de transporte.

Cuadro 2. Distribución modal del tráfico entre algunos pares $O$ - D. Fuente: elaboración propia en base a información de CNRT, sitios Web de las empresas de combis, Plataforma 1o y Central de Pasajes y visitas a las cabeceras de la ciudad de Buenos Aires (2017).

\begin{tabular}{|c|c|c|c|c|c|c|}
\hline \multirow{2}{*}{ Par O - D } & \multirow{2}{*}{$\begin{array}{c}\text { Ruta } \\
\text { Nacional № }\end{array}$} & \multirow{2}{*}{$\begin{array}{l}\text { Distancia } \\
(\mathrm{Km})\end{array}$} & \multicolumn{4}{|c|}{ Distribución modal del tráfico (\%) } \\
\hline & & & $\begin{array}{c}\text { Serv. } \\
\text { Regulares }\end{array}$ & Combis & $\begin{array}{l}\text { Automóvil } \\
\text { particular }\end{array}$ & Total \\
\hline Chivilcoy - CABA & 5 & 170 & $17 \%$ & $19 \%$ & $63 \%$ & $100 \%$ \\
\hline Bragado - CABA & 5 & 220 & $14 \%$ & $19 \%$ & $67 \%$ & $100 \%$ \\
\hline 9 de Julio - CABA & 5 & 270 & $20 \%$ & $19 \%$ & $62 \%$ & $100 \%$ \\
\hline Roque Pérez - CABA & 205 & 140 & $12 \%$ & $27 \%$ & $61 \%$ & $100 \%$ \\
\hline Saladillo - CABA & 205 & 185 & $11 \%$ & $24 \%$ & $65 \%$ & $100 \%$ \\
\hline 25 de Mayo - CABA & 205 & 230 & $7 \%$ & $27 \%$ & $66 \%$ & $100 \%$ \\
\hline Gral. Alvear - CABA & 205 & 245 & $22 \%$ & $19 \%$ & $60 \%$ & $100 \%$ \\
\hline Bolívar - CABA & 205 & 335 & $10 \%$ & $34 \%$ & $56 \%$ & $100 \%$ \\
\hline Carmen de Areco - CABA & 7 & 150 & $4 \%$ & $27 \%$ & $68 \%$ & $100 \%$ \\
\hline Chacabuco - CABA & 7 & 215 & $9 \%$ & $15 \%$ & $76 \%$ & $100 \%$ \\
\hline San Pedro - CABA & 9 & 170 & $11 \%$ & $30 \%$ & $59 \%$ & $100 \%$ \\
\hline Baradero - CABA & 9 & 191 & $13 \%$ & $16 \%$ & $71 \%$ & $100 \%$ \\
\hline San Pedro - Rosario & 9 & 157 & $4 \%$ & $24 \%$ & $72 \%$ & $100 \%$ \\
\hline Baradero - Rosario & 9 & 178 & $3 \%$ & $19 \%$ & $78 \%$ & $100 \%$ \\
\hline
\end{tabular}


Cuadro 3. Frecuencias de servicios de ómnibus regulares y de combis en algunos pares $O-D$. Fuente: elaboración propia en base a información de CNRT, sitios Web de las empresas de combis, Plataforma 10 y Central de Pasajes y visitas a las cabeceras de la ciudad de Buenos Aires (2017).

\begin{tabular}{|c|c|c|c|c|}
\hline \multirow{2}{*}{ Par O - D } & \multicolumn{2}{|c|}{$\begin{array}{c}\text { Frecuencias semanales (ida y } \\
\text { vuelta) }\end{array}$} & \multicolumn{2}{|c|}{ Tarifas / precios (\$) } \\
\hline & $\begin{array}{l}\text { Ómnibus serv. } \\
\text { Regulares }\end{array}$ & Combis & $\begin{array}{l}\text { Ómnibus serv. } \\
\text { Regulares }\end{array}$ & Combis \\
\hline Chivilcoy - CABA & 35 & 100 & 225 & 200 \\
\hline Bragado - CABA & 42 & 82 & 290 & 230 \\
\hline 9 de Julio - CABA & 40 & 66 & 290 & 280 \\
\hline Roque Pérez - CABA & 70 & 102 & 178 & 215 \\
\hline Saladillo - CABA & 56 & 74 & 244 & 240 \\
\hline 25 de Mayo - CABA & 14 & 80 & 240 & 190 \\
\hline Gral. Alvear - CABA & 42 & 46 & 324 & 300 \\
\hline Bolívar - CABA & 56 & 84 & 450 & 400 \\
\hline $\begin{array}{l}\text { Carmen de Areco - } \\
\text { CABA }\end{array}$ & 64 & 30 & 185 & 200 \\
\hline Chacabuco - CABA & 182 & 28 & 300 & 280 \\
\hline San Pedro - CABA & 126 & 106 & 214 & 200 \\
\hline Baradero - CABA & 96 & 40 & 182 & 190 \\
\hline San Pedro - Rosario & 126 & 40 & 190 & 200 \\
\hline Baradero - Rosario & 112 & 16 & 210 & 220 \\
\hline
\end{tabular}

Cuadro 4. Pasajeros anuales transportados en diferentes modos de transporte en algunos pares $O-D$. Fuente: elaboración propia en base a datos de CELADI, indagaciones realizadas en Once y Alto Palermo y sitios Web de empresas transportistas (2017).

\begin{tabular}{|c|c|c|c|c|c|c|}
\hline \multirow[b]{2}{*}{ Pares O - D } & \multirow[b]{2}{*}{ Ruta } & \multirow[b]{2}{*}{$\begin{array}{l}\text { Distancia } \\
\quad(\mathrm{km})\end{array}$} & \multicolumn{4}{|c|}{ Pasajeros por año } \\
\hline & & & $\begin{array}{l}\text { Ómnibus } \\
\text { servicios } \\
\text { regulares }\end{array}$ & Combis & $\begin{array}{l}\text { Automóvil } \\
\text { particular }\end{array}$ & Total \\
\hline Chivilcoy - CABA & 5 & 170 & 81.000 & 90.000 & 295.000 & 466.000 \\
\hline Bragado - CABA & 5 & 220 & 51.000 & 66.000 & 238.000 & 355.000 \\
\hline 9 de Julio - CABA & 5 & 270 & 57.500 & 55.000 & 181.000 & 293.500 \\
\hline Roque Pérez - CABA & 205 & 140 & 32.000 & 72.000 & 166.000 & 270.000 \\
\hline Saladillo - CABA & 205 & 185 & 31.000 & 65.000 & 180.000 & 276.000 \\
\hline 25 de Mayo - CABA & 205 & 230 & 18.000 & 70.000 & 170.000 & 258.000 \\
\hline Gral. Alvear - CABA & 205 & 245 & 43.000 & 30.000 & 120.000 & 193.000 \\
\hline Bolívar - CABA & 205 & 335 & 22.000 & 60.000 & 60.000 & 142.000 \\
\hline $\begin{array}{l}\text { Carmen de Areco - } \\
\text { CABA }\end{array}$ & 7 & 150 & 4.000 & 25.000 & 62.000 & 91.000 \\
\hline Chacabuco - CABA & 7 & 215 & 13.500 & 20.000 & 115.000 & 148.500 \\
\hline San Pedro - CABA & 9 & 170 & 28.000 & 80.000 & 155.000 & 263.000 \\
\hline Baradero - CABA & 9 & 191 & 23.000 & 30.000 & 130.000 & 183.000 \\
\hline San Pedro - Rosario & 9 & 157 & 4.000 & 23.000 & 68.000 & 95.000 \\
\hline Baradero - Rosario & 9 & 178 & 1.500 & 10.000 & 40.000 & 51.500 \\
\hline
\end{tabular}




\section{Q Bibliografía}

» Asociación de Fabricantes de Automotores (ADEFA). Anuarios. Varios años. Buenos Aires, Argentina. Lugar de publicación: www.adefa.com.ar. Recuperado de: http://www.adefa.org.ar/es/estadisticas-anuarios.

» Barañano Cid, M. (2016) El paradigma de las movilidades: contribuciones y limitaciones. Proyecto de investigación Departamento de Ciencias Políticas y Sociales del Instituto Universitario Europeo de Florencia y Departamento de Sociología de la Universidad de Cambridge, Universidad Complutense de Madrid. Lugar de publicación: https://docplayer.es/. Recuperado de https:// docplayer.es/79186423-El-paradigma-de-las-movilidades-contribuciones-ylimitaciones-1-margarita-baranano-cid-universidad-complutense-de-madrid. html (01/07/2019).

» Barbero, J. (2017) Disertación ¿Hay un nuevo paradigma en el transporte? Conferencia o3 UNSAM. Buenos Aires.

» Blanco, J. (2015). Territorio, circulación y redes: articulaciones y tensiones. En Annablume Ed. Território e circulação. A dinámica contraditória da globalização. Arroyo, M. y Rita de Cássia Ariza da Cruz, organizadoras (p. 15-36). USP. San Pablo.

»Cámara Empresaria de Larga Distancia (2016). Estudio de corredores. Mimeo

»Ciccolella, P. y Vecslir, L. (2012). Dinámicas, morfologías y singularidades en la reestructuración metropolitana de Buenos Aires. Revista Iberoamericana de Urbanismo 8. Buenos Aires. (pp. 23-41)

» Ferraresi, F. (2012). La competitividad del ómnibus, en jaque. Lugar de publicación: www.aaeta.org.ar Recuperado en http://www.aaeta.org.ar/content/ la-competitividad-del-\%C3\%B3mnibus-en-jaque. AAETA.

" Germani, G. (1980). El surgimiento del peronismo: el rol de los obreros y de los migrantes internos. En Mora y Araujo, Manuel y Llorente, Ignacio. El voto peronista. Buenos Aires. Editorial Sudamericana.

"Gutiérrez, A. (2012). ¿Qué es la movilidad? Elementos para (re) construir las definiciones básicas del campo del transporte. Bitácora 21: 61 - 74 Universidad Nacional de Colombia, Bogotá.

»Hernández, D. y Witter, R. (2011). Entre la Ingeniería y la Antropología: Hacia un Sistema de Indicadores Integrado sobre Transporte Publico y Movilidad. Revista Transporte y Territorio 4, pp. 1-9. Universidad de Buenos Aires.

»Instituto Nacional de Estadísticas y Censos (2013). Estimaciones y proyecciones de población 2010 - 2040. Total del país. Serie Análisis Demográfico 35. Buenos Aires.

» Ministerio de Planificación Federal, Inversión Pública y Servicios de la Nación. Buenos Aires (2015). ATLAS ID. Plan Estratégico Territorial. Indicadores de desarrollo de territorial de la República Argentina. Buenos Aires.

» Ministerio de Planificación Federal, Inversión Pública y Servicios (2011). Plan Estratégico Territorial Avance II: Argentina Urbana. Buenos Aires.

" Ministerio del Interior y Transporte, Instituto Argentino de Transporte (2015), Plan Federal Estratégico de Transporte. Movilidad y Logística (PFETRA). Buenos Aires. 
» Müller, A. (2010). Una reforma sin desenlace: El caso del autotransporte interurbano de pasajeros. CESPA, Documento de Trabajo 17. Buenos Aires.

"Olivieri, R. (1996). Transporte por automotor de pasajeros en el ámbito interurbano $e$ internacional. Breves nociones sobre su régimen jurídico. La experiencia desreguladora, doctrina y jurisprudencia. Ed. San Julián. Buenos Aires.

"Parodi, E. (2011). Transporte Automotor interurbano de pasajeros. Voces en el Fenix, 2, 9. (pp 56-63). Buenos Aires.

»Pastoriza, E. (2008). Estado, gremios y hoteles. Mar del Plata y el peronismo. Estudios Sociales 34, Universidad Nacional de Mar del Plata. Lugar de publicación: journals.openedition.org Recuperado de: http:// https://journals. openedition.org/nuevomundo/36472

»Ricot, C. (2012) Constelación Christaller: hexágonos sobre la Pampa. Café de las Ciudades Revista digital, 11, 111-112. Buenos Aires.

»Rodrigue, J.-P. (2017). The Geography of Transport Systems. Lugar de publicación: transportgeography.org. New York.

"Sánchez, J. (2017). El mercado doméstico de transporte interurbano de pasajeros en Argentina. Lugar de publicación: Fundación Centro de Estudios para el Cambio Estructural. Recuperado de: http://fcece.org.ar/publicaciones/ page/4\%. Buenos Aires.

»Sánchez, J. (Coord.) (2009.). Transporte Público Automotor de Pasajeros en la Argentina. Ed. Edutecne. Centro Tecnológico de Transporte, Tránsito y Seguridad Vial (C3T). Universidad Tecnológica Nacional. Buenos Aires.

"Santos, M. (2006). A natureza do espaço. Técnica e Tempo. Razão e Emoção. EDUSP Universidade de São Paulo.

»Sheller, M. y Urry, J. (2006). The new mobilities paradigm. Environment and Planning A, 38:207-226.

"Sheller, M. y Urry, J. (2018). Mobilizing the new mobilities paradigm, Revista del área de estudios urbanos, Instituto de Investigación Gino Germani, Facultad de Ciencias Sociales (UBA). Quid 16, 10 (pp 333-355).

"Subsecretaría de Movilidad Sustentable y Dirección Nacional de Planificación de Transporte Interurbano e Internacional de Pasajeros. Secretaría de Planificación del Transporte. Ministerio de Transporte (2017). Indicadores para definir la zona de influencia de un servicio urbano. Buenos Aires.

»Zunino, D. (2018). Ciudades, prácticas y representaciones. Notas para un análisis cultural de la movilidad como experiencia urbana. Lugar de publicación: Tempo Social, revista de sociología da USP, 30, 2, (pp. 35-54). Recuperado de: https://doi.org/10.11606/0103-2070.ts.2018.142171.

\section{Páginas web}

»Empresa Estrella Tour. Recuperado de https://www.estrellatour.com.ar/\#!/inicio/

》Empresa Buses Chivilcoy. Recuperado de http://www.buseschivilcoy.com.ar/

»Empresa Santorini. Recuperado de http://www.santoriniturismo.com/

"Empresa Airbus S.A. Recuperado de https://airbussa.negocio.site/ 
»Empresa Travel Planning. Recuperado de https://www.travelplanning.com.ar/ contacts.html

"Empresa Bus Line. Recuperado de https://www.facebook.com/pages/category/ Bus-Line/San-Pedro-Bus-San-Pedro-1084433548237832/

»Empresa Turismo Rucar. Recuperado de http://www.turismorucar.com.ar/

»Empresa Turismo Billoch. Recuperado de http://www.turismobilloch.com.ar/ horarios.html

»Empresa Luc-Zac. Recuperado de https://www.facebook.com/pages/category/ Tour-Agency/Luc-Zac-879186238773040/

"Empresa Travel Bus. Recuperado de Portal 25 de Mayo. https://www.web25.com. ar/travel-bus/

»Empresa BB Viajes. Recuperado de http://www.bbviajes.com.ar/

»Empresa Del Sur Bus. Recuperado de http://www.delsurbus.com.ar/

»Empresa Lobos Bus. Recuperado de https://lobosbus.com.ar

»Empresa Cañuela Bus. Recuperado de http://canuelasbus.com.ar/

\section{Jorge Sánchez / josanctte@gmail.com}

Licenciado en Economía (UBA). Especialista en temas de movilidad de personas y bienes. Laboralmente se ha desarrollado en el ámbito público y como consultor de empresas y de organismos internacionales (BID, CAF y Banco Mundial). Docente e investigador del Instituto de Transporte de la UNSAM. Autor y/o colaborador en numerosas publicaciones en congresos y revistas nacionales y del exterior.

\section{Daniela Miglierina / danielamiglierina@hotmail.com}

Licenciada en Sociología (UBA), Magíster en Economía Urbana (UTDT) y Doctoranda en Geografía (UBA). Actividad laboral en la Dirección de Planificación del Ministerio de Transporte. 